\title{
Level of nutrient intake affects mammary gland gene expression profiles in preweaned Holstein heifers ${ }^{1}$
}

\author{
P. Piantoni, ${ }^{\star}$ K. M. Daniels, $†$ R. E. Everts, ${ }^{\star 2}$ S. L. Rodriguez-Zas, ${ }^{\star}$ H. A. Lewin, ${ }^{\star} \ddagger$ W. L. Hurley, ${ }^{\star}$ R. M. Akers, $\S$ \\ and J. J. Loor*3 \\ *Department of Animal Sciences, University of Illinois, 1207 West Gregory Drive, Urbana 61801 \\ †Department of Animal Science, The Ohio State University, Wooster 44691 \\ łInstitute for Genomic Biology, University of Illinois, 1206 West Gregory Drive, Urbana 61801 \\ §Dairy Science Department, Virginia Tech, Blacksburg 24061
}

\section{ABSTRACT}

Bovine mammary parenchyma (PAR) and fat pad (MFP) development are responsive to preweaning level of nutrient intake. We studied transcriptome alterations in PAR and MFP from Holstein heifer calves (n $=6 /$ treatment) fed different nutrient intakes from birth to ca. $65 \mathrm{~d}$ age. Conventional nutrient intake received $441 \mathrm{~g}$ of dry matter (DM)/d of a control milk replacer (MR) [CON; $20 \%$ crude protein (CP), $20 \%$ fat, DM basis]. Calves in the accelerated nutrition groups received $951 \mathrm{~g} / \mathrm{d}$ of high-protein/low-fat MR (HPLF; 28\% CP, $20 \%$ fat, DM basis), $951 \mathrm{~g} / \mathrm{d}$ of high-protein/high-fat MR (HPHF; $28 \%$ CP, $28 \%$ fat, DM basis), or 1,431 g/d of HPHF $(\mathrm{HPHF}+)$ MR. Out of 13,000 genes evaluated, over 1,500 differentially expressed genes (DEG) were affected (false discovery rate $<0.10$ ) by level of nutrient intake in PAR or MFP. Feeding HPLF versus CON resulted in the most dramatic changes in gene expression, with 278 and 588 DEG having $\geq 1.5$-fold change in PAR and MFP. In PAR, the most-altered molecular functions were associated with metabolism of the cell (molecular transport and lipid metabolism) with most of the genes downregulated in HPLF versus CON. In MFP, DEG also were primarily associated with metabolism but changes also occurred in genes linked to cell morphology, cell-to-cell signaling, and immune response. Compared with CON, feeding HPHF or $\mathrm{HPHF}+$ did not result in substantial additional effects on DEG beyond those observed with HPLF. The pentose phosphate, mitochondrial dysfunction, and ubiquinone biosynthesis pathways were among the

\footnotetext{
Received May 16, 2011.

Accepted January 5, 2012.

${ }^{1}$ Funding for the gene expression and bioinformatics analysis was provided by the Cooperative State Research, Education, and Extension Service, US Department of Agriculture, under Hatch projects ILLU538-307 and ILLU-538-391 (both to J. J. Loor).

${ }^{2}$ Current address: Sequenom Inc., 3595 John Hopkins Court, San Diego, CA 92121.

${ }^{3}$ Corresponding author: jloor@illinois.edu
}

most enriched due to HPLF versus CON in PAR and were inhibited, whereas glycosphingolipid biosynthesis, arachidonic acid metabolism, and eicosanoid synthesis pathways were among the most enriched due to HPLF versus $\mathrm{CON}$ in MFP and were inhibited. These responses suggest that, in PAR, doubling nutrient intake from standard feeding rates inhibited energy metabolism and activity of oxidative pathways that partly serve to protect cells against oxidative stress. The MFP in those heifers appeared to decrease production of lipid-derived metabolites that may play roles in signaling pathways within the adipocyte. Overall, results indicated that prepubertal/preweaned mammary transcriptome is responsive to long-term enhanced nutrient supply to achieve greater growth rates before weaning. The biological significance of these results to future milk production remains to be elucidated.

Key words: mammary gland development, dairy calf, gene expression

\section{INTRODUCTION}

Heifer rearing typically has focused on achieving earlier puberty and earlier breeding to increase profitability on farms (Ettema and Santos, 2004). Overfeeding during the allometric phase of mammary growth (2 to 3 mo of age through puberty) can increase ADG and accelerate onset of puberty (Meyer et al., 2006a). An increase in nutrient intake during this phase may impair mammary development (Sejrsen et al., 1982) and decrease milk yield at first lactation (Radcliff et al., 2000), but decreased first-lactation milk yield is not always observed (Waldo et al., 1998). However, more recent research suggests that chronological age and not level of nutrient intake determines the rate of bovine mammary parenchyma (PAR) mass accumulation in the prepubertal heifer (Meyer et al., 2006a,b).

The preweaning period (birth through 2 to 3 mo of age) is the first developmental stage in which nutrition can stimulate greater rates of lean gain (Blome et al., 2003; Brown et al., 2005b), presumably without causing 
impaired mammary development (Brown et al., 2005a; Meyer et al., 2006a). An increase in udder size during this period appears to be more related to an increase in bovine mammary fat pad (MFP) and connective tissue than PAR tissue (Sinha and Tucker, 1969; Meyer et al., 2006a). However, recent studies showed that greater energy and protein intake during the preweaning period (i.e., enhancing nutrient intake) has the potential to increase both PAR mass (Brown et al., 2005a) as well as epithelial cell proliferation (Meyer et al., 2006b). This may translate into greater first-lactation milk yield in animals fed such diets. For instance, Moallem et al. (2010) showed that calves allowed two 30-min periods per day to drink either fresh whole milk to satiety [as opposed to milk replacer (MR)], averaged $10 \%$ more milk and $7 \%$ more ECM in their first lactation than heifers fed MR. Also, a recent study by Davis Rincker et al. (2011) showed that heifers fed a diet designed to achieve $0.68 \mathrm{~kg}$ of daily gain versus a conventional diet to attain $0.45 \mathrm{~kg}$ of daily gain before weaning and managed the same thereafter, had no differences in energycorrected or age-uncorrected 305-d milk yield; however, a tendency existed to produce more age-uncorrected ECM in heifers fed the intensified diet.

Prepubertal level of nutrient intake has proven to be an important stimulus that can affect bovine mammary mRNA expression and potentially the rate of tissue development. Early studies mentioned above indicated that level of nutrient intake during the preweaning period could have long-lasting effects on productivity and profitability. Therefore, identifying molecular mechanisms that are susceptible to different levels of nutrient intake in PAR and MFP before weaning might help us more thoroughly understand mammary gland development and, in the future, achieve practical goals such as maximizing PAR mass and, consequently, milk production. The general hypothesis we sought to test was that enhanced level of nutrient intake affects MFP and PAR tissue gene expression. Specific objectives were to evaluate large-scale gene expression profiles in PAR and MFP tissues using bioinformatics analysis and to relate gene network expression to tissue development and function.

\section{MATERIALS AND METHODS}

\section{Animals and Sampling}

All procedures were conducted under protocols approved by the Virginia Tech Institutional Animal Care and Use Committee. Specific details on feeding and management have been reported previously (Hill et al., 2008; Daniels et al., 2009) and a brief summary is presented in the Supplemental Material (available online at http://www.journalofdairyscience.org/). Heifers (n $=5-6$ per treatment) were euthanized at ca. $65 \mathrm{~d}$ age by phenobarbitol injection (Euthasol; Virbac AH Inc., Fort Worth, TX; $10 \mathrm{mg} / \mathrm{kg}$ of BW) and exsanguinated. Internal organs and mammary glands were removed and their weights recorded (Hill et al., 2008). Mammary fat pad was collected from the fat adjacent to the body wall, whereas PAR was collected from the macroscopic central mass of the epithelial portion of the gland. Subsamples of PAR and MFP were snap-frozen in liquid $\mathrm{N}_{2}$, shipped overnight to the University of Illinois, and then stored in liquid $\mathrm{N}_{2}$ until RNA extraction (details are given in the Supplemental Material; available online at http://www.journalofdairyscience.org/).

\section{Microarrays}

A bovine oligonucleotide microarray developed at the University of Illinois (Loor et al., 2007) with more than 13,000 bovine oligonucleotides (70-mers) was used to identify large-scale changes in gene expression. Details on the development, annotation, and use of this microarray have been reported previously (Loor et al., 2007). Methods for microarray hybridizations and scanning were as reported by Loor et al. (2007). Briefly, slides were hydrated, dried, and placed in a UV cross-linker (UV Stratalinker 1800; Stratagene, Agilent Technologies Inc., Santa Clara, CA) for approximately $5 \mathrm{~min}$. Slides were washed with $0.2 \%$ SDS solution, rinsed with distilled deionized $\mathrm{H}_{2} \mathrm{O}$, and placed in warm prehybridization solution for $45 \mathrm{~min}$ at $42^{\circ} \mathrm{C}$. The same amount of Cy3- or Cy5-labeled mammary cDNA and a reference standard RNA pool (made of different bovine tissues) were co-hybridized using a dye-swap design (i.e., 2 microarrays per tissue sample). Slides were incubated for $40 \mathrm{~h}$ at $45^{\circ} \mathrm{C}$ before scanning. Criteria for evaluation of slide quality included identification of number of spots with a minimum median signal intensity of 3 standard deviations above background, keeping slides with a minimum of 20,000 spots with minimum median signal intensity of 3 standard deviations above background in both $\mathrm{Cy} 3$ and $\mathrm{Cy} 5$ channels, and keeping slides with a minimum mean intensity of 400 relative fluorescent units in both $\mathrm{Cy} 3$ and $\mathrm{Cy} 5$ channels across the entire slide.

\section{Data Analyses}

Data from a total of 82 microarrays (38 PAR and 44 MFP; 41 samples from 19 animals contributing both PAR and MFP and 3 animals contributing only MFP) were normalized for dye and array effects (i.e., lowess normalization and array centering) and used for statistical analysis. All data were analyzed using the 
Proc MIXED procedure of SAS (SAS Institute Inc., Cary, NC). Fixed effects in the model were tissue, level of nutrient intake [441 g of DM/d of control MR (CON; $20 \%$ CP, $20 \%$ fat, DM basis), $951 \mathrm{~g} / \mathrm{d}$ of highprotein/low-fat MR (HPLF; $28 \%$ CP, $20 \%$ fat, DM basis), $951 \mathrm{~g} / \mathrm{d}$ of high-protein/high-fat MR (HPHF; $28 \%$ CP, $28 \%$ fat, DM basis), or 1,431 g/d of HPHF $(\mathbf{H P H F}+)]$, and dye, whereas random effects included calf and microarray. Separate analyses were conducted to evaluate treatment effects within PAR and within MFP. Results of tissue-specific differences in the transcriptome have already been published (Piantoni et al., 2010). Raw $P$-values were adjusted using the Benjamini and Hochberg false discovery rate (FDR; Reiner et al., 2003). Differences in relative expression between diets were considered significant at an FDR-adjusted 0.10 within PAR and within MFP, which was equivalent to unadjusted $P<0.01$. Scheffé's adjustment of $P$-values between treatment was used to control the experimentwise type I error. The cutoff for the Scheffé-adjusted $P$-value was 0.05 for treatment effect, unless otherwise specified. Data from real-time quantitative PCR (qPCR) were analyzed as described by Piantoni et al. (2008). The statistical model (SAS Institute Inc., Cary, $\mathrm{NC}$ ) included the fixed effect of treatment and the random effect of heifer within treatment. The MIXED procedure of SAS was used.

\section{Data Mining and Verification by $q P C R$}

These details are presented in the Supplemental Material and results are in Supplemental Tables 14 and 15 (http://www.journalofdairyscience.org/). Briefly, microarray data were mined using the gene-enrichment approach [also known as the overrepresented approach (ORA); Huang et al., 2009] via the web-based software Ingenuity Pathway Analysis (IPA; Ingenuity Systems Inc., Redwood City, CA). The ORA is based on the assumption that in order for pathways, functions, or terms in a given gene list to be biologically relevant, they have to be overrepresented [i.e., must be present in the gene list at a greater proportion compared with the background or a list of genes selected randomly among the ones available (i.e., annotated microarray platform)]. As in previous studies with bovine mammary glands, using a similar FDR cutoff for overall treatment effects (i.e., FDR <0.10; Li and Capuco, 2008), only those right-tailed Fisher exact test $P$-values $<0.05$ were used to determine enrichment (e.g., Loor et al., 2007; Swanson et al., 2009). Using an FDR adjustment of those $P$-values did not lead to significantly enriched functions/pathways, which is biologically unlikely (Loor et al., 2011). Rather, such response underscored one important limitation of applying the ORA ap- proach during bioinformatics [Huang et al., 2009; e.g., when the list of differentially expressed genes (DEG) is large, the likelihood of finding significantly enriched terms is lowered if FDR adjustments are applied]. For a thorough discussion of the ORA approach and its limitations the reader can evaluate Huang et al. (2009) and Loor et al. (2011). We attempted to provide biological interpretation of the ORA results by using the "effect on function" feature in IPA. Further details on this evaluation approach can be found in the Supplemental Material (http://www.journalofdairyscience.org/).

Selection of genes for qPCR was based on level of fold change in the microarray data set as well as on their putative biological roles in PAR and MFP (e.g., FOS, PPARG, LEPR; Piantoni et al., 2008). For qPCR verification of microarray results, oligonucleotide sequences of those targets selected for verification were first analyzed via BLAST (http://blast.ncbi.nlm.nih. gov/Blast.cgi) for homology with the respective target genes. In MFP, we verified the expression pattern (i.e., significance or direction of the response, or both) of 23 out of 32 genes $(\sim 72 \%)$ and in PAR 26 out of 31 genes ( $\sim 84 \%)$. In MFP, we observed opposite responses by qPCR compared with microarray for $A 2 M, A C T B$, CPT1C, CSN3, LPL, PRLR, S100A8, S100G, and TP53, whereas in PAR, we observed opposite responses for CSN3, DGAT2, LEP, RXRG, and TP53. When verification was evaluated via correlation (e.g., $\mathrm{Li}$ and Capuco, 2008) using data for all genes examined, we observed the correlation coefficient $(\mathrm{r})=0.71$ in PAR and $\mathrm{r}=0.40$ in MFP. The correlations without including genes with opposite responses were $\mathrm{r}=0.94$ in PAR and $\mathrm{r}=0.87$ in MFP. The degree of verification we obtained was similar to or greater than previous work in bovine mammary epithelial cells ( $\sim 55-88 \%$; Stiening et al., 2008), bovine embryos ( 76\%; Smith et al., 2009), or bovine liver (60\%; Connor et al., 2010). Comparisons across studies, however, must be done with caution because of inherent differences in qPCR methodology, suitability of internal control genes used, and approach to establish congruency between microarrays and qPCR (i.e., correlation vs. actual statistical analysis).

\section{RESULTS AND DISCUSSION}

In the present study, MR were formulated to support increased daily gains either through varying the level of protein and fat or the rate of intake (Hill et al., 2008). In this context, the most relevant comparisons from an industry and biological standpoint were those between HPLF and CON and between HPHF and CON. Both HPLF and HPHF were fed at twice the level of CON, which more closely reflects current industry practices. The weight of MFP and PAR averaged 131.3 and 8.8 
$\mathrm{g}$, respectively, in calves fed HPLF and 84.1 and $5.9 \mathrm{~g}$, respectively, in calves fed CON (Daniels et al., 2009). In contrast, the weight of MFP and PAR averaged 192.2 and $10.1 \mathrm{~g}$, respectively, in calves fed HPHF, and 324.8 $\mathrm{g}$ and $84.1 \mathrm{~g}$, respectively, in calves fed HPHF+ (Daniels et al., 2009). Differences in PAR tissue weight due to treatments were not statistically significant; however, enhanced nutrient intake resulted in greater MFP weight relative to CON (Daniels et al., 2009).

Our data, for the most part, confirmed previous studies evaluating the effects of level of nutrient intake on calf performance and mammary gland composition (e.g., Blome et al. 2003; Brown et al., 2005a,b). Previous data showed that feeding higher levels of nutrients enhances growth rate and is often accompanied by greater deposition of structural and lean tissue without additional fat deposition (Blome et al., 2003; Brown et al., 2005b). Extraparenchymal fat and total PAR increased when a high level of nutrient intake was fed from birth, suggesting that an increase in level of nutrient intake also affects rate of mammary development (Brown et al., 2005a). Meyer et al. (2006b) also suggested that a high level of nutrient intake from birth, and specifically at $\mathrm{BW}<100 \mathrm{~kg}$, might increase PAR cell proliferation in the prepubertal mammary gland. Therefore, mammary tissue of young animals (BW $<100 \mathrm{~kg}$ ) may have an inherently greater capacity for enhanced rates of cell proliferation. First-lactation milk production from heifers that had been fed different MR or whole milk as calves also has been evaluated (Terré et al., 2009; Moallem et al. 2010), with results suggesting that higher intake of nutrients has the potential to result in greater milk production.

Growth performance and mammary development results from calves in the present study were discussed by Daniels et al. (2009), and seemed to confirm the notion that an increase in mammary size during the preweaning period is more related to enlargement of MFP than PAR tissue (Sinha and Tucker, 1969). This was supported by the fact that, in PAR, no differences were observed between HPHF and HPHF + for total tissue weight (average $12.3 \mathrm{~g}$ ), total lipid content (2 g), total DNA content $(27.3 \mathrm{~g})$, total protein content $(0.48 \mathrm{~g})$, cell proliferation rate, and amount of telomerase $(0.5 \mathrm{amol} / \mathrm{mg}$ of mammary protein; Daniels et al., 2009). Nevertheless, the experiment had few animals per level of nutrient formulation, which makes it difficult to totally discard the possibility of an effect of higher nutrient intake on PAR tissue at this early stage of development. Despite the lack of effect on PAR, the opposite was the case for MFP (e.g., feeding HPHF and HPHF + vs. HPLF increased total lipid by $\sim 68$ and 100 g; Daniels et al., 2009). In fact, the relative amount of lipid in MFP as a proportion of total MFP mass was approximately $50 \%$ with HPLF but increased to approximately $69 \%$ and approximately $72 \%$ when HPHF and HPHF + were fed. Those relationships seem to agree with data from Capuco et al. (1995), showing that the proportion of adipocytes relative to epithelium was markedly greater in prepubertal calves fed a highenergy diet designed to increase the rate of gain.

Despite the marked differences in MFP tissue weights observed when feeding HPLF compared with HPHF or $\mathrm{HPHF}+$, the former resulted in the most changes in gene expression profiles relative to CON. In fact, no obvious changes were observed at the level of gene expression between the HPHF and HPHF + diets compared with $\mathrm{CON}$ that could explain the increases in mass of MFP observed. Therefore, because of the practical relevance of feeding HPLF, the discussion of transcriptomics changes for both PAR and MFP is focused primarily on the comparison of HPLF with CON.

\section{Effects of Level of Nutrient Intake on PAR}

Number of DEG. A total of 1,641 DEG had a significant overall effect of level of nutrient intake (FDR $<0.10$ ) in PAR (Table 1). When comparing the number of DEG from higher intake of nutrients with CON, feeding HPLF resulted in 598 DEG, constituting the largest effect (Table 1). Feeding HPHF + resulted in the lowest number of DEG compared with CON. Overall, a total of 108 (33 upregulated, 75 downregulated) and 118 (29 upregulated, 89 downregulated) genes were simultaneously affected by higher nutrient intake compared with CON (Table 1; for details on the actual genes see Supplemental Tables 4-7, available in the online version of this paper). The number of DEG with an arbitrary 1.5-fold or greater expression when comparing HPLF with CON was relatively smaller (i.e., 278) than might have been expected, given the differences in nutrient intakes between both treatments. Nevertheless, this small difference on DEG is not surprising when we consider that PAR tissue weight in response to HPLF did not differ statistically from CON (Daniels et al., 2009). Besides, greater glucose concentration with HPLF, blood insulin, growth hormone, and IGF-1 were not statistically significant when comparing HPLF with CON (Daniels et al., 2008). Biologically, however, numerical differences in hormones and growth factors (e.g., greater IGF-1 with HPLF; Daniels et al., 2008) might have been associated with some of the transcriptomics responses observed.

Overall Effects of Feeding HPHF and HPHF+. Despite the much smaller numbers of DEG affected, and available for enrichment analysis, results from the bioinformatics analysis (Supplemental Table 14; http:// www.journalofdairyscience.org/) revealed that genes 
Table 1. Summary of statistical results in parenchyma and fat pad of heifer calves fed enhanced levels of nutrient intake (HPLF, HPHF, or

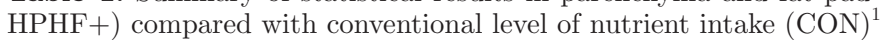

\begin{tabular}{|c|c|c|c|c|c|c|c|c|c|c|}
\hline DEG (no.) & Tissue & $\begin{array}{l}\text { Increased } \\
\text { nutrient intake } \\
\text { vs. CON }\end{array}$ & \multicolumn{2}{|c|}{$\begin{array}{l}\text { DEG affected } \\
\text { simultaneously }\end{array}$} & \multicolumn{6}{|c|}{ Number of $\mathrm{DEG}^{3}$} \\
\hline \multirow[t]{3}{*}{1,641} & \multirow[t]{3}{*}{ Parenchyma } & HPLF & & & 268 & 330 & 598 & 130 & 148 & 278 \\
\hline & & HPHF & & & 81 & 155 & 236 & 11 & 41 & 52 \\
\hline & & $\mathrm{HPHF}+$ & & & 74 & 122 & 196 & 17 & 17 & 34 \\
\hline \multirow{3}{*}{1,541} & \multirow{3}{*}{ Fat pad } & HPHF & & & 56 & 178 & 234 & 28 & 54 & 82 \\
\hline & & HPHF+ & & & 52 & 159 & 211 & 20 & 56 & 76 \\
\hline & & Total & 29 & 89 & & & & & & \\
\hline
\end{tabular}

${ }^{1} \mathrm{HPLF}=951 \mathrm{~g} / \mathrm{d}$ of high-protein/low-fat milk replacer $(28 \% \mathrm{CP}, 20 \%$ fat, DM basis); HPHF $=951 \mathrm{~g} / \mathrm{d}$ of high-protein $/$ high-fat milk replacer $(28 \%$ CP, $28 \%$ fat, DM basis); HPHF $+=1,431 \mathrm{~g} / \mathrm{d}$ of HPHF; CON $=441 \mathrm{~g}$ of DM/d of control milk replacer (20\% CP, $20 \%$ fat, DM basis). The complete list of differentially expressed genes (DEG) affected simultaneously in response to increased nutrient intake can be found in Supplemental Materials (http://www.journalofdairyscience.org/).

${ }^{2}$ Increased nutrient intake compared with CON.

${ }^{3}$ Upregulation and downregulation of DEG in parenchyma or fat pad tissue relative to the reference RNA sample. See Materials and Methods for additional details.

affected by either HPHF or HPHF + compared with HPLF elicited the overall upregulation of pathways associated with oxidative stress and apoptosis, pentose phosphate pathway, and cellular growth and development, but at the expense of a downregulation of pathways that would (a priori) appear necessary for the cell to maintain homeostasis (e.g., glutathione metabolism) in the face of marked increase in nutrient availability. It was noteworthy that pathways associated with genome repair, phospholipid biosynthesis, glycolysis, and neuronal death were not affected by greater intake of nutrients. Thus, it appeared that PAR was able to tolerate greater nutrient availability but might be particularly sensitive to oxidative stress, which could be alleviated via supplementation of antioxidants (e.g., vitamin E and selenium) or cellular glutathione precursors (e.g., methionine).

Because we already established that PPAR $\gamma$ and its lipogenic gene targets are more predominately expressed in MFP than PAR (Piantoni et al., 2010), the enlargement of MFP observed with HPHF and $\mathrm{HPHF}+$ likely was driven by greater uptake of dietary long-chain FA rather than de novo synthesis. In fact, such response would partly explain the lack of enrichment in the bioinformatics analysis of genes associated with lipogenesis (see Supplemental Table 16; http:// www.journalofdairyscience.org/). From that standpoint, it was quite remarkable that MFP from calves fed HPHF or HPHF + compared with HPLF experienced an overall induction of glutathione metabolism and glycosphingolipid biosynthesis without changes in pathways associated with cell survival, repair, and removal of damaged proteins (Supplemental Table 17; http://www.journalofdairyscience.org/). Further studies in this area of nutrition with a greater number of biological replicates seem warranted and would help to confirm the present findings based on relatively few DEG.

Top Biological Functions and Canonical Pathways. In PAR, significant molecular functions in the comparison of HPLF with CON were molecular transport (67 DEG), cellular development (34 DEG), lipid metabolism (42 DEG), carbohydrate metabolism (40 DEG), AA metabolism (11 DEG), cell morphology (27 molecules), and cellular growth and proliferation (12 DEG) (Supplemental Table 2; http://www.journalofdairyscience.org/). The most-enriched molecular functions were primarily related to cell metabolism (i.e., molecular transport and lipid, carbohydrate, and AA metabolism) and, in general, genes in these functions were downregulated. Interestingly, cellular development, cell morphology, and cellular growth and proliferation also included genes that were primarily downregulated despite the fact that calves fed HPLF had a numerical increase in PAR tissue weight (8.8 vs. 5.9 g; Daniels et al., 2009). In contrast, several genes associated with FA uptake (CD36) and energy metabolism (UCP1), as well as genes involved in cellular mitogenesis and response to inflammation (e.g., F2R) were upregulated $>1.5$ fold by feeding HPLF. Among metabolism-related functions, functional analysis revealed that overall quantity of lipid and carbohydrate, as well as production of lipid were overall inhibited with feeding HPLF compared with CON (Table 2). Such response might have been related to the fact that enhancing intake of nutrients with high-protein MR typically favors leaner tissue 
Table 2. Functional evaluation of molecular and cellular functions that were enriched in differentially expressed genes (DEG) in parenchymal tissue from calves fed an enhanced level of nutrient intake as HPLF compared with the conventional level of nutrient intake $(\mathrm{CON})^{1}$

\begin{tabular}{|c|c|c|}
\hline Function & $\begin{array}{c}\text { Genes } \\
\text { affected (no.) }\end{array}$ & $\begin{array}{l}\text { Main effect } \\
\text { on function }\end{array}$ \\
\hline Molecular transport & 67 & $\downarrow$ Quantity of lipid \\
\hline Cellular development & 34 & Lifespan of cells ${ }^{3}$. differentiation of epidermal cells ${ }^{3}$ \\
\hline Carbohydrate metabolism & 40 & $\downarrow$ Quantity of carbohydrate \\
\hline Cell morphology & 27 & $\leftrightarrow$ Shape change of blood cells; $\downarrow$ shape \\
\hline Cell signaling & 27 & $\leftrightarrow$ Tyrosine phosphorylation of protein; $\downarrow$ release of $\mathrm{Ca}^{2+}$ \\
\hline Nervous system development and function & 40 & $\downarrow$ Activation of neuroglia \\
\hline Vitamin and mineral metabolism & 16 & $\downarrow$ Release of $\mathrm{Ca}^{2+}$ \\
\hline Hematological system development and function & 29 & $\leftrightarrow$ Aggregation of blood cells \\
\hline $\begin{array}{l}\text { Tissue development } \\
\text { late }\end{array}$ & 27 & $\leftrightarrow$ Aggregation of blood cells \\
\hline Post-translational modification & 17 & $\leftrightarrow$ Tyrosine phosphorylation of protein \\
\hline
\end{tabular}

${ }^{1} \mathrm{HPLF}=951 \mathrm{~g} / \mathrm{d}$ of high-protein/low-fat milk replacer $(28 \% \mathrm{CP}, 20 \%$ fat, DM basis); CON = $441 \mathrm{~g}$ of DM/d of control milk replacer (20\% CP $20 \%$ fat, DM basis). Included are functions with at least 5 molecules affected.

${ }^{2}$ Arrows indicate stimulation $(\uparrow)$ of a particular effect on function or an inhibition $(\downarrow)$ of a particular effect on function according to criteria outlined in the Supplemental Materials (http://www.journalofdairyscience.org/). The horizontal arrows $(\leftrightarrow)$ indicate that the effect on function was neither inhibited nor stimulated.

${ }^{3}$ Effects on functions that were considered to be affected (not stimulated or inhibited in a clear fashion) due to lack of information in the Ingenuity Pathway Analysis database (Ingenuity Systems Inc., Redwood City, CA).

mass deposition than standard protein MR (Blome et al., 2003), and that lipid content in PAR ( $\mathrm{mg} / \mathrm{g}$ of PAR) did not increase significantly in calves fed HPLF compared with CON (Daniels et al., 2009).

Among the genes uniquely affected by HPLF and with a relatively large fold change was F2R (verified by qPCR; Supplemental Table 10; http://www.journalofdairyscience.org/). This gene was associated with molecular transport, lipid metabolism, carbohydrate metabolism, as well as with cell morphology and cellular growth and proliferation (Supplemental Table 2). The overall evaluation of the likely functional significance of changes in F2R and other DEG (both up- and downregulated) in response to HPLF compared with $\mathrm{CON}$ indicated that PAR responded by downregulating energy metabolism pathways leading to a decrease in biological processes related to lipid synthesis and accumulation (Tables 3 and 4). The upregulation of F2R alone due to HPLF is not entirely surprising because in nonmammary epithelial cells, F2R encodes the thrombin receptor, which is required for activation of the phosphoinositide 3-kinase (PI3K)-Akt pathway. This signaling pathway is crucial for self-regeneration, active growth, and regression of nonmammary epithelial cells (Feutz et al., 2008). Thus, despite a likely involvement of this gene (and others among DEG in Supplemental Table 2; http://www.journalofdairyscience.org/) in cell growth, the overall changes revealed a broader set of adaptations that apparently resulted in a decrease in cellular metabolism when nutrient availability was enhanced by feeding HPLF.
Among cellular adaptations of potential importance was the inhibition of oxidative pathways (i.e., those that potentially prevent excessive buildup of reactive oxygen species and fall within the IPA categories of mitochondrial dysfunction and ubiquinone biosynthesis, which takes place in mitochondria). Derangements in the mitochondrial dysfunction pathway have been related with oxidative stress (Hashiguchi et al., 2004) and apoptosis (Eckert et al., 2003). It could be envisioned that enhanced nutrient delivery to mammary PAR cells when the feeding rate was doubled (i.e., due to HPLF) signaled adaptations to utilize those substrates for metabolism rather than maintaining flux through pathways, which, under basal conditions, provide most of the ATP required by cells (e.g., oxidative phosphorylation).

Another gene that was upregulated by HPLF compared with CON by qPCR was CAMK2A (Figure 1 ). In nonruminants, $C A M K 2 A$ is ubiquitously expressed and is predominantly cytoplasmic (Hook and Means, 2001). Upon activation, one of the target genes of $C A M K 2 A$ is FOS, which also was numerically upregulated by HPLF in PAR (Figure 1). The cyclic AMP (cAMP) response element-binding protein (CREB1), a ubiquitous transcription regulator that binds the response element of hundreds of target genes, is another substrate for activated CAMK2A (Montminy, 1997). The majority of nuclear CREB protein is bound to chromatin and ca. $50 \%$ becomes phosphorylated upon cAMP stimulus (Montminy, 1997). In fact, it is thought that CREB1 actually resides as a component of certain RNA poly- 
Table 3. Most significant canonical pathways, number of genes affected, number of genes up or downregulated ( $\uparrow / \downarrow$ ), effect related to end product (up- or downregulated or no change: $\uparrow, \downarrow$, or $\leftrightarrow$, respectively), function of the pathway, and genes affected in parenchyma tissue from calves fed an enhanced level of nutrient intake as HPLF compared with the conventional level of nutrient intake $(\mathrm{CON})^{1}$

\begin{tabular}{|c|c|c|c|c|c|c|}
\hline Pathway & $\begin{array}{c}-\log \\
(P \text {-value })\end{array}$ & $\begin{array}{l}\text { No. of } \\
\text { genes }\end{array}$ & $\uparrow / \downarrow$ & $\begin{array}{l}\text { Effect related } \\
\text { to end product }\end{array}$ & $\begin{array}{l}\text { Function } \\
\left(\text { from IPA }^{2}\right)\end{array}$ & Genes \\
\hline Pentose phosphate & $2.35 \mathrm{E}+00$ & 5 & $0 / 5$ & $\downarrow$ & \multirow{2}{*}{$\begin{array}{l}\text { Substrates for glycolysis, } \\
\text { gluconeogenesis, and purine, pyrimidine, } \\
\text { and histidine metabolism } \\
\beta \text {-Oxidation of FA; protection } \\
\text { against oxidative stress }\end{array}$} & $\begin{array}{l}G P I, A L D O B, G 6 P D \\
P F K M, B C K D H B\end{array}$ \\
\hline Mitochondrial dysfunction & $1.78 \mathrm{E}+00$ & 10 & $1 / 9$ & $\downarrow$ & & $\begin{array}{l}\text { SDHA, NDUFV1, NDUFB9, } \\
\text { SOD2, PRDX5, NDUFA6, CPT1B, } \\
\text { NDUFB7, PSEN2, COX6A2 }\end{array}$ \\
\hline $\mathrm{PXR} / \mathrm{RXR}^{3}$ activation & $1.75 \mathrm{E}+00$ & 6 & $0 / 6$ & $\downarrow$ & \multirow[t]{3}{*}{$\begin{array}{l}\text { Transport of xenobiotics and other } \\
\text { organic compounds; phase II metabolism } \\
\text { of xenobiotics (conjugation); drug- } \\
\text { induced regulation of gluconeogenesis } \\
\text { and lipid metabolism }\end{array}$} & $\begin{array}{l}\text { PRKACB, GSTA2, ABCC2, } \\
\text { FOXO3, INSR, SLCO1B3 }\end{array}$ \\
\hline One carbon pool by folate & $1.74 \mathrm{E}+00$ & 3 & $1 / 2$ & $\downarrow$ & & FTCD, TYMS, MTHFR \\
\hline Androgen and estrogen metabolism & $1.57 \mathrm{E}+00$ & 4 & $1 / 3$ & $\downarrow$ & & $\begin{array}{l}\text { HSD3B1, AKR1D1, } \\
\text { UGT1A6, HSD17B8 }\end{array}$ \\
\hline Coagulation system & $1.51 \mathrm{E}+00$ & 4 & $1 / 3$ & $\downarrow$ & \multirow[t]{2}{*}{$\begin{array}{l}\text { Extrinsic and intrinsic pathways; } \\
\text { fibrin degradation }\end{array}$} & $F 10, F 2 R, F G B, F 2$ \\
\hline Ubiquinone biosynthesis & $1.31 \mathrm{E}+00$ & 5 & $0 / 5$ & $\downarrow$ & & $\begin{array}{l}\text { NDUFV1, NDUFB9, NDUFA6, } \\
\text { NDUFB } 7 \text {, BCKDHB }\end{array}$ \\
\hline
\end{tabular}

${ }^{1} \mathrm{HPLF}=951 \mathrm{~g} / \mathrm{d}$ of high-protein/low-fat milk replacer $(28 \% \mathrm{CP}, 20 \%$ fat, DM basis); CON $=441 \mathrm{~g}$ of DM/d of control milk replacer (20\% CP, $20 \%$ fat, DM basis). Remaining comparisons can be found in the Supplemental Material (http://www.journalofdairyscience.org/).

${ }^{2} \mathrm{IPA}=$ Ingenuity Pathway Analysis (Ingenuity Systems Inc., Redwood City, CA).

${ }^{3} \mathrm{PXR} / \mathrm{RXR}=$ pregnane $\mathrm{X}$ receptor/retinoid $\mathrm{X}$ receptor. 
Table 4. Functional evaluation of molecular and cellular functions that were enriched in differentially expressed genes (DEG) in fat pad tissue from calves fed an enhanced level of nutrient intake as HPLF compared with the conventional level of nutrient intake (CON)

\begin{tabular}{|c|c|c|}
\hline Function & $\begin{array}{c}\text { Genes } \\
\text { affected (no.) }\end{array}$ & $\begin{array}{l}\text { Main effect } \\
\text { on function }^{2}\end{array}$ \\
\hline Cell morphology & 76 & $\begin{array}{l}\leftrightarrow \text { Outgrowth of neurites; } \leftrightarrow \text { outgrowth of plasma } \\
\text { membrane projections; size of cells }\end{array}$ \\
\hline Nervous system development and function & 62 & $\leftrightarrow$ Outgrowth of neurites; $\downarrow$ growth of neurites \\
\hline Cell-to-cell signaling and interaction & 45 & Adhesion of blood cells ${ }^{3}$ \\
\hline Hematological system development and function & 48 & $\begin{array}{l}\text { Cell movement of granulocytes }{ }^{3} \text {; cell movement } \\
\text { of myeloid cells }{ }^{3} \text {; adhesion of leukocytes }\end{array}$ \\
\hline Immune and lymphatic system development and function & 45 & Adhesion of leukocytes ${ }^{3}$ \\
\hline Tissue development & 38 & Aggregation of blood cells ${ }^{3}$ \\
\hline Post-translational modification & 38 & $\leftrightarrow$ Activation of protein \\
\hline Immune response & 51 & Inflammatory response $^{3}$ \\
\hline \multicolumn{3}{|c|}{$\begin{array}{l}{ }^{1} \mathrm{HPLF}=951 \mathrm{~g} / \mathrm{d} \text { of high-protein/low-fat milk replacer }(28 \% \mathrm{CP}, 20 \% \text { fat, DM basis); CON }=441 \mathrm{~g} \text { of DM/d of control milk replacer }(20 \% \mathrm{CP} \text {, } \\
20 \% \text { fat, DM basis). Included are functions with at least } 5 \text { molecules affected. } \\
{ }^{2} \text { Arrows indicate stimulation }(\uparrow) \text { of a particular effect on function or an inhibition }(\downarrow) \text { of a particular effect on function according to criteria } \\
\text { outlined in Supplemental Materials (http://www.journalofdairyscience.org/). The horizontal arrows }(\leftrightarrow) \text { indicate that the effect on function was } \\
\text { neither inhibited nor stimulated. } \\
{ }^{3} \text { Effects on functions that were considered to be affected (not stimulated or inhibited in a clear fashion) due to lack of information in the } \\
\text { Ingenuity Pathway Analysis database (Ingenuity Systems Inc., Redwood City, CA). }\end{array}$} \\
\hline
\end{tabular}

merase II complexes. In this regard, it was interesting that POLR2H mRNA was ca. 2-fold greater in response to HPLF than in CON (Supplemental Table 10; http://www.journalofdairyscience.org/). Although neither CAMK2A nor POLR2H were mapped to the top-enriched IPA molecular functions (Supplemental Table 2), it could be possible that external stimuli such as insulin, IGF-1, glucose, and additional molecules or nutrients themselves may have elicited changes in PAR gene expression through upregulation of CAMK2A and its putative downstream targets FOS, CREB, and POLR2H.

\section{Effects of Higher Nutrient Intake on MFP Tissue}

Number of DEG. More than 1,500 DEG had a significant overall effect (FDR <0.10) of higher nutrient intake in MFP. In the HPLF versus CON comparison, more DEG were present in MFP than PAR (Table 1). This likely reflects the fact that adipose tissue is more responsive to greater nutrient intake (Meyer et al., 2006a) and potentially more biologically active at this point of development than the PAR tissue. An increase in MFP weight corresponded with an increase in nutrient intake across all diets, with $\mathrm{HPHF}+$ resulting in the highest MFP tissue weight (Daniels et al., 2009). Despite the substantial differences in MFP deposition between HPLF and HPHF +, the response in number of DEG was similar to that observed in PAR (i.e., feed- ing HPLF resulted in the most changes compared with CON; Table 1).

Top Biological Functions and Canonical Pathways. In comparison with PAR, a substantially greater number of DEG belonged to several molecular functions that were affected in MFP in response to HPLF. Some of the most enriched and significant molecular and cellular functions affected by HPLF compared with CON were cell morphology (76 DEG), molecular transport (74 DEG), cellular development (70 DEG), immune response (51 DEG), cell-to-cell signaling and interaction (45 DEG), and lipid metabolism (43 DEG) (Supplemental Table 3; http://www.journalofdairyscience.org/). The large numbers of DEG associated with cell morphology, cellular development, cell-to-cell signaling, and immune response could be related to the fact that, at this stage in mammary development, the MFP is growing due to both hypertrophy and hyperplasia (Avram et al., 2007). The stable hydrolysis of triglycerides and phospholipids and the suggestion of reduced intracellular $\mathrm{Ca}^{2+}$ (Table 4) could be related to increased hypertrophy as well. In that regard, functional evaluation of enriched pathways underscored the fact that greater nutrient intake may have resulted in lower synthesis of secondary signaling molecules derived from phospholipids or arachidonic acid and eicosanoid metabolism, or both (Table 5). Thus, it could be possible that these lipid-derived signaling molecules are important for MFP enlargement via hyperplasia. 


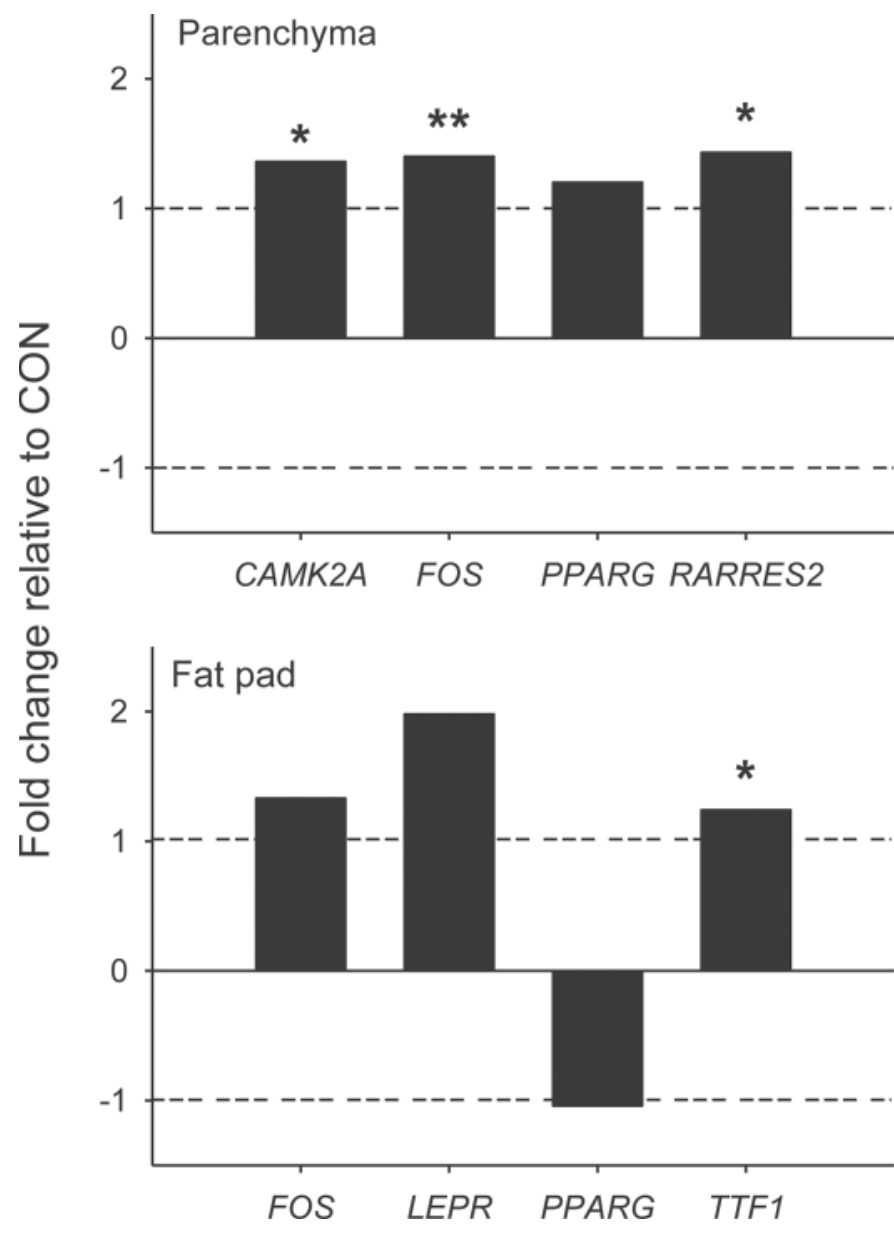

Figure 1. Expression pattern [fold change due to $951 \mathrm{~g} / \mathrm{d}$ of highprotein/low-fat milk replacer (HPLF; $28 \% \mathrm{CP}, 20 \%$ fat, DM basis) vs. $441 \mathrm{~g}$ of DM/d of control milk replacer (CON; $20 \% \mathrm{CP}, 20 \%$ fat, DM basis)] of selected genes in parenchyma and fat pad. ${ }^{*} P<0.05$; ${ }^{* *} P$ $=0.15$. A value of 1.0 or $-1.0=$ no change over $\mathrm{CON}$ and is denoted by a dashed line.

A signature gene that is associated with lipogenesis in nonruminants is THRSP [Thyroid hormone responsive (SPOT14 homolog, rat); Supplemental Table 11; http://www.journalofdairyscience.org/]. Thyroid hormone and insulin act synergistically to enhance lipogenic rates in white and brown adipocytes in rodents, a process driven at least in part via coordinated induction of ACACA, FASN, and THRSP mRNA expression (Freake and Moon, 2003). We did not detect differences due to HPLF on mRNA of PPARG (Figure 1), which is primarily expressed in MFP (Piantoni et al., 2010) and encodes a key nuclear receptor that drives lipogenesis (Desvergne et al., 2006). Thus, our results suggest that adipogenesis and lipid filling in MFP during the preweaning period was sensitive to enhanced nutrition and it seems, to some extent, that it is partly under control of THRSP through its effectors insulin, thyroid hormone, and likely glucose. Because insulin was nu- merically lower and glucose significantly higher in blood from calves fed HPLF compared with CON (Daniels et al., 2008), these animals did not seem to have experienced insulin insensitivity, which is in agreement with an involvement of THRSP in MFP lipogenesis.

In MFP as in PAR, several DEG were classified across different molecular function categories, including F2R, INSR, IL1B, and S100A8 (Table 5). Expression of F2R was upregulated by HPLF in MFP as it was in $\mathrm{PAR}$, suggesting that signaling cascades transduced via this receptor are important in the development of both tissue compartments. The proinflammatory cytokine IL1B was downregulated due to HPLF, which partly agrees with recent data showing that a higher nutrient intake in heifer calves of slightly greater development than ours (i.e., ca. $100 \mathrm{~kg}$ vs. $86.7 \mathrm{~kg}$ of BW; Daniels et al., 2009) did not result in greater MFP mRNA abundance of TNF (Thorn et al., 2008). Thorn et al. (2006) concluded that, although expansion of the MFP occurred as heifers grew from 100 to $350 \mathrm{~kg}$ of BW, this was related to greater mRNA of inflammatory proteins (TNF, IL-6, plasminogen activator inhibitor-1, and transforming growth factor- $\beta 1$ ) and these were unlikely to depress PAR growth, based on their lack of effects on in vitro cell proliferation assays.

Despite those previous findings, our results suggest that other inflammatory-related proteins are responsive to higher intake of nutrients in MFP before weaning (e.g., S100A8, which was ca. 2-fold greater in MFP due to HPLF; Supplemental Table 11; http://www. journalofdairyscience.org/) and leads to formation of calprotectin, which plays a prominent role in the regulation of inflammatory processes and immune response, and serves as a marker for the influx of phagocytes during inflammation (Korndörfer et al., 2007). Because excessive fat deposition is often associated with a mild proinflammatory state in nonruminants (Boullu-Ciocca et al., 2008), it is possible that feeding HPLF elicited a similar effect.

Additional genes upregulated with HPLF in MFP with potentially important roles in regulation of gene transcription were TAF9 (Supplemental Table 11; http://www.journalofdairyscience.org/) and TTF1 (Figure 1). The former encodes a protein member of the TATA-binding protein that is used by all RNA polymerases during the process of gene transcription (Johnson et al., 2003), whereas TTF1 encodes a transcription termination factor during RNA polymerase I transcription. Based on fold changes, both TAF9 and TTF1 responded to HPLF marginally. However, it is well established in nonruminants that changes in TAF expression are often lower than 2 fold in response to cellular signaling events, but the resulting changes in target gene expression are more dramatic (Johnson et 
Table 5. Most significant canonical pathways, number of genes up- or downregulated $(\uparrow / \downarrow)$, effect related to end product (up- or downregulated or no change: $\uparrow, \downarrow$, or $\leftrightarrow$, respectively), pathway function, and molecules affected in fat pad tissue from calves fed an enhanced level of nutrient intake as HPLF compared with the conventional level of nutrient intake $(\mathrm{CON})$

\begin{tabular}{|c|c|c|c|c|c|c|}
\hline Pathway & $\begin{array}{c}-\log \\
(P \text {-value })\end{array}$ & $\begin{array}{l}\text { No. of } \\
\text { genes }\end{array}$ & $\uparrow / \downarrow$ & $\begin{array}{l}\text { Effect related } \\
\text { to end product }\end{array}$ & Function (from IPA ${ }^{2}$ ) & Molecules \\
\hline Glycosphingolipid biosynthesis-lactoseries & $2.47 \mathrm{E}+00$ & 4 & $1 / 3$ & $\downarrow$ & \multirow{5}{*}{$\begin{array}{l}\text { Phosphorylation- } \\
\text { dephosphorylation (PD) } \\
\text { system; phosphorylation and } \\
\text { internalization of parallel } \\
\text { fiber AMPAR } \text { A endocytosis }^{3}\end{array}$} & ABO, ST3GAL1, FUT1, FUT3 \\
\hline Synaptic long-term depression & $2.13 \mathrm{E}+00$ & 15 & $8 / 7$ & $\downarrow$ & & $\begin{array}{l}\text { PPP2R5C, MAPK1, GUCY2D, } \\
\text { ADCY4, GNA11, GNAQ, PLA2G2A, } \\
\text { GNA14, ITPR1, PRKG1, PPP2R1A, } \\
\text { RRAS2, RNF111, PLCB3, PLCB1 }\end{array}$ \\
\hline Glycosphingolipid biosynthesis-neolactoseries & $1.98 \mathrm{E}+00$ & 5 & $0 / 5$ & $\downarrow$ & & $\begin{array}{l}\text { ABO, FUT1, B3GNT1, } \\
\text { FUT3, ST8SIA3 }\end{array}$ \\
\hline Arachidonic acid metabolism & $1.92 \mathrm{E}+00$ & 10 & $2 / 8$ & $\downarrow$ & & $\begin{array}{l}\text { LTA4H, GPX3, ALOX15B, GGT5, } \\
\text { CYP2E1, RNF111, EPHX2, } \\
\text { ALOX12, PLA2G2A, CYP2S1 }\end{array}$ \\
\hline Chondroitin sulfate biosynthesis & $1.69 \mathrm{E}+00$ & 5 & $5 / 0$ & $\uparrow$ & & $\begin{array}{l}\text { GAL3ST2, XYLT2, XYLT1, } \\
\text { HS3ST5, SULT1B1 }\end{array}$ \\
\hline Eicosanoid signaling & $1.39 \mathrm{E}+00$ & 6 & $1 / 5$ & $\downarrow$ & \multirow[t]{3}{*}{$\begin{array}{l}\text { Inflammatory and allergic } \\
\text { response; hyperalgesia, } \\
\text { analgesia; cell proliferation, } \\
\text { angiogenesis; among others }\end{array}$} & $\begin{array}{l}\text { LTA4H, ALOX15B, RNF111, } \\
\text { PTGER3, ALOX12, PLA2G2A }\end{array}$ \\
\hline Fructose and mannose metabolism & $1.34 \mathrm{E}+00$ & 6 & $1 / 5$ & $\downarrow$ & & \multirow{3}{*}{$\begin{array}{l}\text { AKR1A1, PMM1, KHK, } \\
\text { GALK1, FUK, PFKFB2 } \\
\text { UCHL1, AKR1A1, } \\
\text { UGT2A1, BCKDHB } \\
\text { GABRA5, GABRB1, GABRE, } \\
\text { GABRA1, GABRA2 }\end{array}$} \\
\hline Pentose and glucuronate interconversions & $1.33 \mathrm{E}+00$ & 4 & $1 / 3$ & $\downarrow$ & & \\
\hline $\mathrm{GABA}^{4}$ receptor signaling & $1.32 \mathrm{E}+00$ & 5 & $0 / 5$ & $\downarrow$ & $\begin{array}{l}\text { Proteasomal degradation; } \\
\text { activation of } \mathrm{G} \text { proteins; } \\
\text { inhibition of adenylate } \\
\text { cyclase; inhibition of calcium } \\
\text { and potassium channels }\end{array}$ & \\
\hline
\end{tabular}

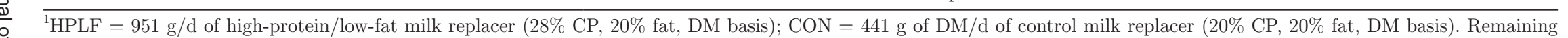
ㄱ. comparisons can be found in the Supplementary Material (http://www.journalofdairyscience.org/).

․․․․․ $\quad{ }^{2}$ IPA = Ingenuity Pathway Analysis (Ingenuity Systems Inc., Redwood City, CA).

ก ${ }^{3} \mathrm{AMPAR}=\alpha$-amino-3-hydroxy-5-methyl-4-isoxazolepropionic acid receptor.

$\stackrel{\circ}{\Phi}$. $\quad{ }^{4} \mathrm{ABA}=\gamma$-aminobutyric acid. 
al., 2003). A $25 \%$ increase in TAF mRNA in fibroblasts produced a 2-fold or greater increase in expression of 20 genes and a 2-fold repression of 30 genes (Johnson et al., 2003). Thus, the involvement of TAF9 and TTF1 in transcriptional adaptations in MFP due to greater nutrient intake are likely of biological relevance. The potential role of estrogen receptor signaling in MFP development preweaning is discussed in Supplemental Materials (http://www.journalofdairyscience.org/). The downstream targets of TAF9 in bovine mammary tissue remain to be determined.

\section{CONCLUSIONS}

Considering the number of transcripts represented on the microarray platform and the marked differences in nutrient intake we studied, gene expression analysis at the end of the treatment period revealed fewer than expected DEG. However, it should be kept in mind that these transcriptomic adaptations represent endpoint responses to long-term higher nutrient intake (i.e., it is reasonable to suspect that temporal adaptations led to the stable expression patterns we uncovered (also see Daniels et al., 2009). Judging by the modest responses observed in tissue weights and blood plasma metabolites and hormones, the transcriptional responses observed due to enhancing nutrient intake by feeding HPLF appear relevant. Overall, enhancing nutrient intake beyond levels from what is commonly used in accelerated calf rearing programs (i.e., HPHF or HPHF+) during the first $2 \mathrm{mo}$ of life did not affect substantially the mammary PAR and MFP transcriptome. Some of the transcriptomic changes might underlie the observed differences in tissue mass and development due to HPLF compared with CON [i.e., a numerical $\sim 21 \%$ increase in MFP weight ( $\mathrm{g}$ of MFP/100 kg of empty $\mathrm{BW}$ ) and $18 \%$ increase in PAR weight (g of PAR/100 $\mathrm{kg}$ of empty BW); Daniels et al., 2009]. However, we did not find molecular signatures with the higher-fat MR that could explain differences observed in tissue mass. We conclude that enhancing nutrient intake to twice the intake of conventional MR might be sufficient to enhance mammary gland development through alterations in mRNA expression across several molecular functions and pathways. The biological significance of these results to future milk production remains to be elucidated.

\section{ACKNOWLEDGMENTS}

The help of Daniel E. Graugnard and Massimo Bionaz (University of Illinois, Urbana) during portions of this work is gratefully appreciated.

\section{REFERENCES}

Avram, M. M., A. S. Avram, and W. D. James. 2007. Subcutaneous fat in normal and diseased states: 3. Adipogenesis: From stem cell to fat cell. J. Am. Acad. Dermatol. 56:472-492.

Blome, R. M., J. K. Drackley, F. K. McKeith, M. F. Hutjens, and G. C. McCoy. 2003. Growth, nutrient utilization, and body composition of dairy calves fed milk replacers containing different amounts of protein. J. Anim. Sci. 81:1641-1655.

Boullu-Ciocca, S., V. Achard, V. Tassistro, A. Dutour, and M. Grino. 2008. Postnatal programming of glucocorticoid metabolism in rats modulates high-fat diet-induced regulation of visceral adipose tissue glucocorticoid exposure and sensitivity, and adiponectin and proinflammatory adipokines gene expression in adulthood. Diabetes 57:669-677.

Brown, E. G., M. J. VandeHaar, K. M. Daniels, J. S. Liesman, L. T. Chapin, J. W. Forrest, R. M. Akers, R. E. Pearson, and M. S. Weber Nielsen. 2005a. Effect of increasing energy and protein intake on mammary development in heifer calves. J. Dairy Sci. 88:595-603.

Brown, E. G., M. J. VandeHaar, K. M. Daniels, J. S. Liesman, L. T. Chapin, D. H. Keisler, and M. S. Weber Nielsen. 2005b. Effect of increasing energy and protein intake on body growth and carcass composition of heifer calves. J. Dairy Sci. 88:585-594.

Capuco, A. V., J. J. Smith, D. R. Waldo, and C. E. Rexroad Jr. 1995. Influence of prepubertal dietary regimen on mammary growth of Holstein heifers. J. Dairy Sci. 78:2709-2725.

Connor, E. E., S. Kahl, T. H. Elsasser, J. S. Parker, R. W. Li, C. P. Van Tassell, R. L. Baldwin VI, and S. M. Barao. 2010. Enhanced mitochondrial complex gene function and reduced liver size may mediate improved feed efficiency of beef cattle during compensatory growth. Funct. Integr. Genomics 10:39-51.

Daniels, K. M., A. V. Capuco, M. L. McGilliard, R. E. James, and R. M. Akers. 2009. Effects of milk replacer formulation on measures of mammary gland development and composition in Holstein heifers. J. Dairy Sci. 92:5937-5950.

Daniels, K. M., S. R. Hill, K. F. Knowlton, R. E. James, M. L. McGilliard, and R. M. Akers. 2008. Effects of milk replacer composition on selected blood metabolites and hormones in preweaned Holstein heifers. J. Dairy Sci. 91:2628-2640.

Davis Rincker, L. E., M. J. VandeHaar, C. A. Wolf, J. S. Liesman, L. T. Chapin, and M. S. Weber Nielsen. 2011. Effect of intensified feeding of heifer calves on growth, pubertal age, calving age, milk yield, and economics. J. Dairy Sci. 94:3554-3567.

Desvergne, B., L. Michalik, and W. Wahli. 2006. Transcriptional regulation of metabolism. Physiol. Rev. 86:465-514.

Eckert, A., U. Keil, C. A. Marques, A. Bonert, C. Frey, K. Schüssel, and W. E. Müller. 2003. Mitochondrial dysfunction, apoptotic cell death, and Alzheimer's disease. Biochem. Pharmacol. 66:16271634

Ettema, J. F., and J. E. P. Santos. 2004. Impact of age at calving on lactation, reproduction, health, and income in first-parity Holsteins on commercial farms. J. Dairy Sci. 87:2730-2742.

Feutz, A.-C., Y. Barrandon, and D. Monard. 2008. Control of thrombin signaling through PI3K is a mechanism underlying plasticity between hair follicle dermal sheath and papilla cells. J. Cell Sci. 121:1435-1443.

Freake, H. C., and Y. K. Moon. 2003. Hormonal and nutritional regulation of lipogenic enzyme mRNA levels in rat primary white and brown adipocytes. J. Nutr. Sci. Vitaminol. (Tokyo) 49:40-46.

Hashiguchi, K., V. A. Bohr, and N. C. de Souza-Pinto. 2004. Oxidative stress and mitochondrial DNA repair: Implications for NRTIs induced DNA damage. Mitochondrion 4:215-222.

Hill, S. R., K. F. Knowlton, K. M. Daniels, R. E. James, R. E. Pearson, A. V. Capuco, and R. M. Akers. 2008. Effects of milk replacer composition on growth, body composition, and nutrient excretion in preweaned Holstein heifers. J. Dairy Sci. 91:3145-3155.

Hook, S. S., and A. R. Means. 2001. Ca ${ }^{2+} /$ CaM-dependent kinases: From activation to function. Annu. Rev. Pharmacol. Toxicol. 41:471-505. 
Huang, D. W., B. T. Sherman, and R. A. Lempicki. 2009. Bioinformatics enrichment tools: Paths toward the comprehensive functional analysis of large gene lists. Nucleic Acids Res. 37:1-13.

Johnson, S. A., L. Dubeau, R. J. White, and D. L. Johnson. 2003. The TATA-binding protein as a regulator of cellular transformation. Cell Cycle 2:442-444.

Korndörfer, I. P., F. Brueckner, and A. Skerra. 2007. The crystal structure of the human (S100A8/S100A9) ${ }_{2}$ heterotetramer, calprotectin, illustrates how conformational changes of interacting $\alpha$-helices can determine specific association of two EF-hand proteins. J. Mol. Biol. 370:887-898.

Li, R. W., and A. V. Capuco. 2008. Canonical pathways and networks regulated by estrogen in the bovine mammary gland. Funct. Integr. Genomics 8:55-68.

Loor, J. J., R. E. Everts, M. Bionaz, H. M. Dann, R. Oliveira, D. E. Morin, S. L. Rodriguez-Zas, J. K. Drackley, and H. A. Lewin. 2007. Nutrition-induced ketosis alters metabolic and signaling gene networks in liver from periparturient cows. Physiol. Genomics 32:105-116.

Loor, J. J., K. M. Moyes, and M. Bionaz. 2011. Functional adaptations of the transcriptome to mastitis-causing pathogens: The mammary gland and beyond. J. Mammary Gland Biol. Neoplasia $16: 305-322$.

Meyer, M. J., A. V. Capuco, D. A. Ross, L. M. Lintault, and M. E. Van Amburgh. 2006a. Developmental and nutritional regulation of the prepubertal heifer mammary gland: I. Parenchyma and fat pad mass and composition. J. Dairy Sci. 89:4289-4297.

Meyer, M. J., A. V. Capuco, D. A. Ross, L. M. Lintault, and M. E. Van Amburgh. 2006b. Developmental and nutritional regulation of the prepubertal bovine mammary gland: II. Epithelial cell proliferation, parenchymal accretion rate, and allometric growth. J. Dairy Sci. 89:4298-4304.

Moallem, U., D. Werner, H. Lehrer, M. Zachut, L. Livshitz, S. Yakoby, and A. Shamay. 2010. Long-term effects of ad libitum whole milk prior to weaning and prepubertal protein supplementation on skeletal growth rate and first-lactation milk production. J. Dairy Sci. 93:2639-2650.

Montminy, M. 1997. Transcriptional regulation by cyclic AMP. Annu. Rev. Biochem. 66:807-822.

Piantoni, P., M. Bionaz, D. E. Graugnard, K. M. Daniels, R. M. Akers, and J. J. Loor. 2008. Gene expression ratio stability evaluation in prepubertal bovine mammary tissue from calves fed different milk replacers reveals novel internal controls for quantitative polymerase chain reaction. J. Nutr. 138:1158-1164.

Piantoni, P., M. Bionaz, D. E. Graugnard, K. M. Daniels, R. E. Everts, S. L. Rodriguez-Zas, H. A. Lewin, W. L. Hurley, M. Ak- ers, and J. J. Loor. 2010. Functional and gene network analyses of transcriptional signatures characterizing pre-weaned bovine mammary parenchyma or fat pad uncovered novel inter-tissue signaling networks during development. BMC Genomics 11:331.

Radcliff, R. P., M. J. VandeHaar, L. T. Chapin, T. E. Pilbeam, D. K. Beede, E. P. Stanisiewski, and H. A. Tucker. 2000. Effects of diet and injection of bovine somatotropin on prepubertal growth and first-lactation milk yields of Holstein cows. J. Dairy Sci. 83:23-29.

Reiner, A., D. Yekutieli, and Y. Benjamini. 2003. Identifying differentially expressed genes using false discovery rate controlling procedures. Bioinformatics 19:368-375.

Sejrsen, K., J. T. Huber, H. A. Tucker, and R. M. Akers. 1982. Influence of nutrition on mammary development in pre- and postpubertal heifers. J. Dairy Sci. 65:793-800.

Sinha, Y. N., and H. A. Tucker. 1969. Mammary development and pituitary prolactin level of heifer from birth through puberty and during the estrous cycle. J. Dairy Sci. 52:507-512.

Smith, S. L., R. E. Everts, L.-Y. Sung, F. Du, R. L. Page, B. Henderson, S. L. Rodriguez-Zas, T. L. Nedambale, J.-P. Renard, H. A. Lewin, X. Yang, and X. C. Tian. 2009. Gene expression profiling of single bovine embryos uncovers significant effects of in vitro maturation, fertilization and culture. Mol. Reprod. Dev. 76:38-47.

Stiening, C. M., J. B. Hoying, M. B. Abdallah, A. M. Hoying, R. Pandey, K. Greer, and R. J. Collier. 2008. The effects of endocrine and mechanical stimulation on stage I lactogenesis in bovine mammary epithelial cells. J. Dairy Sci. 91:1053-1066.

Swanson, K. M., K. Stelwagen, J. Dobson, H. V. Henderson, S. R. Davis, V. C. Farr, and K. Singh. 2009. Transcriptome profiling of Streptococcus uberis-induced mastitis reveals fundamental differences between immune gene expression in the mammary gland and in a primary cell culture model. J. Dairy Sci. 92:117-129.

Terré, M., C. Tejero, and A. Bach. 2009. Long-term effects on heifer performance of an enhanced-growth feeding programme applied during the preweaning period. J. Dairy Res. 76:331-339.

Thorn, S. R., S. Purup, W. S. Cohick, M. Vestergaard, K. Sejrsen, and Y. R. Boisclair. 2006. Leptin does not act directly on mammary epithelial cells in prepubertal dairy heifers. J. Dairy Sci. 89:1467-1477.

Thorn, S. R., S. Purup, M. Vestergaard, K. Sejrsen, M. J. Meyer, M. E. Van Amburgh, and Y. Y. Boisclair. 2008. Regulation of mammary parenchymal growth by the fat pad in prepubertal dairy heifers: Role of inflammation-related proteins. J. Endocrinol. 196:539-546.

Waldo, D. R., A. V. Capuco, and C. E. Rexroad Jr. 1998. Milk production of Holstein heifers fed either alfalfa or corn silage diets at two rates of daily gain. J. Dairy Sci. 81:756-764. 